\title{
PEMOGRAMAN ROBOT PENARI LEGONG KERATON BALI PADA KRSI (KONTES ROBOT SENI INDONESIA) 2014
}

\author{
M. Dwisnanto Putro, ST. , M. Eng \\ dwisnantoputro@gmail.com \\ Program Studi Teknik Informatika, Fakultas Teknik, Universitas Sam Ratulangi Manado \\ J1. Kampus UNSRAT Bahu - 95115
}

\begin{abstract}
Abstrak - Penelitian ini bertujuan merancang dan mebangun pemograman robot penari legong keraton yang dipentaskan pada KRSI 2014. Robot harus dapat menari tarian Legong Keraton dan bergerak mengikuti alunan musik tarian. Robot penari tersebut dimodifikasi dari robot BIOLOID PREMIUM tipe-A dengan titik sendi derajat kebebasan (DOF) yang dimodifikasi dari yang sebelumnya berjumalah 18 menjadi 21 titik DOF.

Modifikasi dilakukan juga pada Tinggi robot yang sebelumnya hanya $38,7 \mathrm{~cm}$ menjadi $50 \mathrm{~cm}$. Software pemograman yang digunakan pada penelitian ini yaitu RoboPlus. RoboPlus terdiri dari tiga bagian software yaitu RoboPlus Task, RoboPlus Manager dan RoboPlus Motion.

Robot Penari akan mengikuti gerakan tari legong keraton yang terdiri dari empat struktur gerakan utama yaitu papeson, pangawak, pengecet dan pakaad. Dengan masing-masing gerakan memiliki ciri khas yang berbeda. Harapan pada robot penari ini dapat meberikan pengenalan terhadap budaya tari legong keraton dan dapat membangkitkan kecintaan dan pelestarian budayabudaya nasional dalam hal ini tarian legong keraton
\end{abstract}

Kata Kunci : Robot Penari, Tari legong Keraton, RoboPlus

1. Pendahuluan

1.1. Latar Belakang

KRSI (Kontes Robot Seni Indonesia)[1] Merupakan suatu pentas kompetisi perancangan dan pembuatan robot yang disertai unsur-unsur seni dan budaya bangsa indonesia. Robot tersebut berpentas dengan menunjukan kepiawaiannya dalam melakukan gerak tari yang mengikuti alunan musik tarian pengiring. Robot yang dirancang dan dibuat harus menyerupai bentuk manusia yang memiliki kaki, tangan, badan dan kepala. Adapun spesifikasi jumlah sendi robot seni dibatasi dalam aturan kontes KRSI. Tema yang diberikan dalam KRSI 2014 yaitu Tari legong keraton.

Tari legong keraton merupakan tarian yang berasal dari Bali yang sering dipentaskan pada acara adat daerah tersebut. Tarian legong keraton populer dan kerap ditampilkan dalam pertunjukan wisata, tarian ini ditarikan oleh dua orang legong dan seorang condong. Gerakan tarian ini memiliki empat struktur gerakan utama yaitu papeson, pangawak, pengecet dan pakaad.[4]

Teknologi Robot pada masa sekarang berkembang dengan pesat mengimbangi kemajuan teknologi yang ada. Perkembangan robot tidak hanya pada kecanggihan mekaniknya saja, melainkan juga sistem kontrolnya dengan menggunakan sistem komputerisasi. Dengan komponen-komponen robot yang saat ini mudah didapat, sangat membantu dan mempermudah dalam proses pembuatan robot. Pada intinya robot memiliki 3 komponen utama, yaitu sensor, actuator dan controler.[6] Salah satu jenis robot yang populer dalam pengembangannya saat ini yaitu robot humanoid.

Robot humanoid merupakan robot yang memiliki bentuk sama seprti manusia. Selain itu fungsi organ dan indera dalam robot ini juga mirip dengan fungsi organ dan indera yang ada pada manusia. Robot humanoid digunakan pada robot penari karena memiliki unsur yang mirip dengan manusia. Namun tantangan yang dihadapi dalam pembuatan robot penari ini adalah pemograman dan strategi gerakan robot yang harus mengikuti gerakan penari.

Tujuan dalam perancangan dan pembuatan robot ini yaitu selain untuk keikutsertaan kontes KRSI, robot ini juga diharapkan dapat meberikan pengenalan terhadap budaya tari legong keraton pada masyarakat dan dapat membangkitkan kecintaan dan pelestarian budaya-budaya nasional dalam hal ini tarian legong keraton.

\section{Landasan Teori}

2.1. Robot

Robot dalam Arti mula-mula adalah "forcedlabour" yang artinya pekrja paksa, namun dalam pengertian modern kata robot sudah mengalami perluasan makna. Menurut The Robotics International Division of the Society of Manifacturing Engineering (RI/SME), Robot dapat di definisikan sebagai sesuati yang dapat diprogram berulang-ulang, memiliki manipulator yang dapat memindahkan suatu barang/objek dan memiliki fungsi yang banyak membantu pekerjaan manusia[5].

Terdapat tiga komponen utama dalam robot yaitu sensor sebagai komponen yang dapat merespon kondisi lingkungan yang diberikan, actuator sebagai komponen yang menghasilkan gerak mekanik dan 
controler/mikrokontroler sebagai pusat pemikir untuk memproses data dari sensor dan memerintahkan aktuator untuk bertindak. Hubungan dari ketiga komponen ini dapat dilihat pada Gambar 1.[6]

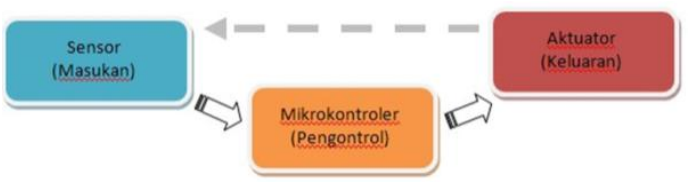

Gbr 1.Hubungan Sensor, Aktuator dan Mikrokontroler pada Robot

\subsection{Robot Humanoid BIOLOID PREMIUM}

Terdapat 4 kategori robot humanoid berkaki yang dikembangkan berdasarkan ukurannya yaitu robot berukuran besar seperti robot LandWalker, robot berukuran manusia seperti musa, robot berukuran kecil-sedang seperti ASIMO dan robot berukuran mini seperti BIOLOID. Robot humanoid berkaki yang tingginya kurang dari $100 \mathrm{~cm}$ termasuk kategori robot mini salah satunya BIOLOID yang tingginya sekitar $38,7 \mathrm{~cm}$.[3]

Pada Robot BIOLOID PREMIUM terdapat 18 buah servo $\mathrm{AX}-12 \mathrm{~A}, 1$ buah gyro sensor 2 axis, 1 buah CM-530, dan perlengkapan serta sensor lainnya untuk pembuatan robot. Fitur-fitur yang digunakan pada penelitian ini adalah servo robot dynamixel, gyrosensor, dan mikrokontroler CM-530. Dengan RoboPlus merupakan software utama dari setiap BIOLOID yang dibuat oleh ROBOTIS. Terdapat tiga bagian utama dari software ini yaitu RoboPlusTask, RoboPlusManager dan RoboPlusMotion.[2]

\subsection{Tari Legong Keraton}

Legong Keraton adalah sebuah tarian klasik Bali yang memiliki pembendaharaan gerak yang sangat komplek dan diikat oleh struktur tabuh pengiring yang konon mendapat pengaruh dari Tari Gambuh. Kata Legong Keraton terdiri dari dua kata yaitu legong dan Keraton. Kata legong diduga berasal dari kata "leg" yang berarti gerak tari yang luwes. Lemah gemulai. Sementara "gong" berarti gambelan. "leg" dan "gong" digabung menjadi legong yang mengandung arti gerakan yang diikat, terutama aksentuasinya oleh gamelan yang mengiringinya. Gerakaan-gerakan tari yang membangun Tari Keraton ini disesuaikan dengan gambelan sehingga tari ini menjadi tarian yang indah, dinamis dan abstrak. Gambelan yang dipakai mengiringi tari ini dalam seni pertunjukan kemasan baru adalah gambelan gong kebyar. Keterampilan dalam membawakan tari Legong, kesesuaiannya dengan penguasaan jalinan wiraga, wirama dan wirasa yang baik, sesuai dengan patokan agem, tandang, dan tangkep.[1]

Struktur tari Legong pada umumnya terdiri dari papeson, pangawak, pengecet, dan pakaad. Ciri khas lain dari tarian ini adalah penarinya menggunakan kipas, kecuali tokoh Condong. Sikap dan Gerak pada tari Condong diantaranya adalah :

1. Ngocok langse adalah gerakan tangan menggetarkan langse (kain tabir)

2. Miles adalah tumit diputar kedalam (kanan - kiri). Gerakan ini misalnya terjadi pada pergantian posisi ngagem.

3. Mungkah lawang adalah gerakan tari yang pertama sebagai awal dari suatu tarian. Maksud dari gerakan ini yaitu untuk membuka langse.

4. Agem kanan adalah berat badan ada pada kaki kanan, jarak kaki kira-kira 1 genggam serta badan condong ke kanan. Tangan kanan sirang mata dan tangan kiri sirang susu.

5. Luk nerudut adalah gerakan kepala ke kanan dan ke kiri yang ditarik secara stakato.

6. Agem kiri adalah berat badan ada pada kaki kiri, jarak kaki kira-kira 1genggam serta badan condong ke kiri. Tangan kiri sirang mata dan tangan kanan sirang susu.

7. Milpil adalah gerakan berjalan juga, hanya ragamnya lebih halus , kadang - kadang injakaninjakan tapak kai lebih dari satu kali.

8. Ngepik adalah leher direbahkan ke kanan dan ke kiri.

Pengawak adalah bagian pokok dari Legong Keraton yang bentuknya sangat abstrak. Pengecet adalah lanjutan daripada pengawak. Bentuknya juga abstrak dan setelah pengecet barulah drama dalam Bagian terakhir yaitu pekaad dimana bagian ini merupakan penutup tari Legong Keraton. Sikap dan gerak pada gerakan tari Legong Keraton ini diantaranya adalah :

1. Ngenjet adalah tangan (posisi tangan) turun sirang pinggang digerakkan bergantian panjang disertai gerak leher dan badan.

2. Ngelus adalah pegangan kipas yang ditekan kedada, posisi ini digabung dengan ngembat kiri dan bernama tanjek panjang digabung dengan ngelukun dan terdapat pula pada gerak ngelung kiri.

3. Nyeregseg adalah gerakan kaki dengan langkah ke samping cepat dan bisa digerakkan kesegala arah.[4]

\section{Perancangan Robot}

Pada perancangan robot penari legong keraton meliputi dua bagian yaitu perancangan body robot dan perancangan perangkat lunak (software) robot.

\subsection{Perancangan Body Robot}

Perancangan Body Robotpenari dibangun dengan memodifikasi robot BIOLOID PREMIUM tipe-A dari segi jumlah degree of freedom (DOF) dan tinggi dari robot. jumlah DOF robot humanoid dilihat berdasarkan jumlah motor servo sebagai penggerak dari robot humanoid. Motor servo yang terdapat pada 
robot BIOLOID PREMIUM adalah motor servo dynamixle tipe $\mathrm{AX}-12$ berjumlah 18 buah. adapun jumlah motor servo masing-masing bagian robot yaitu untuk bagian kaki (kanan dan kiri) yaitu 10 buah, bagian tangan (kanan dan kiri) berjumlah 4 buah dan bagian badan robot yaitu 4 buah.

Tinggi robot ini adalah $38,7 \mathrm{~cm}$ yang diukur berdsarakan posisi tegak robot dari bawah telapak kaki sampai dengan ujung kepala. Berikut Gambar 2(a)yang merupakan ukuran robot BIOLOID PREMIUM tipe-A yang belum dimodifikasi.

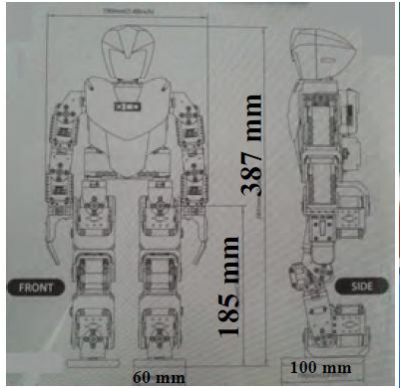

(a)

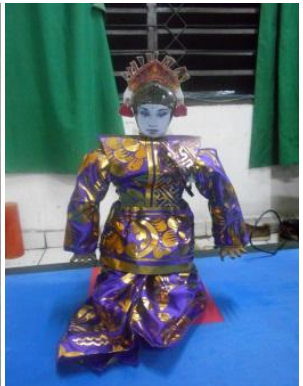

(b)
Gbr 2 (a). Ukuran Robot BIOLOID PREMIUM tipeA. (b). Robot Penari Legong Keraton

Jumlah DOF robot BIOLOID PREMIUM yang sebelumnya 18 buah dimodifikasi menjadi 21 buah motor servo dengan menambah 3 buah motorservo.Penambahan motor servo ditempatkan pada posisi telapak tangan kanan, telapak tangan kiri dan leher kepala untuk membuat robot lebih bergerak dan menari sesuai dengan model tari yang akan ditarikan. Bentuk telapak tangan robot dimodifikasi dengan bahan acrylic dan dibuat dengan bentuk model telapak tangan manusia.Tinggi Robot penari dimodifikasi dari ukuran $38,7 \mathrm{~cm}$ menjadi $50 \mathrm{~cm}$ dengan menambah tinggi robot pada bagian kaki dan kepala. Penambahan rangka robot dengan menggunakan frame BIOLOID PREMIUM. adapun gambar robot penari yang telah di modifikasi dari robot BIOLOID PREMIUM terlihat pada Gambar 2(b).

\subsection{Perancangan Software}

Perancangan software meliputi
softwareRoboPlusManager, software RoboPlusMotion, softwareRoboPlusTask dan diagram alir robot penari legong keraton.

\subsubsection{RoboPlus Manager}

Awalnya ditentukan terlebih dahulu ID untuk masing-masing motor servodynamixle. Ini dilakukan agar ID masing-masing servo tidak bertumpukan dan menghindari tidak terdeteksinya pada saat pengecekan servo. Untuk melakukan pengaturan ID servo dilakukan dengan menggunakan softwareRoboPlusManager dan menghubungkannya ke CM-530. Setelah terhubung, Setelah terhubung barulah dapat mengubah/menambah ID servo ke ID yang diinginkan. Masing-masing servo harus memiliki nomor ID yang berbeda. Pada robot ini nomor ID yang dipakai yaitu nomor 1 hingga 18. Adapun pengaturan lain yang dapat dilakukan pada software ini yaitu batasan torsi, suhu, voltage dan indikator. Dengan software ini juga dapat melihat sudut servo pada posisi saat ini. Pengaturan ID servo pada RoboPlusManager dapat dilihat pada gambar berikut.

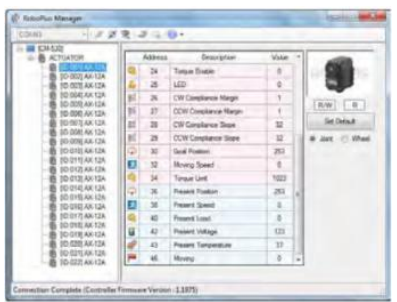

Gbr 3. List Servo pada RoboPlus Manger

\subsubsection{RoboPlusMotion}

Pada software RoboPlus Motion dilakukan proses pembuatan program gerakan tari dari robot. pada software ini ditampilkan semua gerakan yang telah disimpan pada CM-530. Teknik membuat gerakan dilakukan dengan cara poseofstep, poseofrobot dan simulasi 3D. Pose of step merupakan bentuk gerakan yang dibuat pada software ini. Sedangkan pose of robot merupakan bentuk gerakan yang terdapat pada robot. gerakn robot penari dibuat dengan mengatur/mengubah value (nilai) masing-masing servodynamixle. Gerakan tari legong yang dibuat meliputi 5 bagian yaitu zona sembah pembuka, zona 1 (papeson), zona 2 (pengawak), zona 3(pengecet dan pakaad) dan zona sembah penutup. Berikut ini tabel yang merupakan bagian-bagian gerakan tari pada robot penari tari legong keraton.

Tabel 1. Pembagian Zona Untuk Gerakan Robot Penari

\begin{tabular}{|l|l|l|}
\hline Zona & Struktur Tari & Gerakan \\
\hline $\begin{array}{l}\text { Zona } \\
\text { Pembuka }\end{array}$ & $\begin{array}{l}\text { Sembah } \\
\text { pembuka }\end{array}$ & $\begin{array}{l}\text { Gerakan Sembah } \\
\text { Pembuka }\end{array}$ \\
\hline Zona 1 & Papeson & Ngocok langse \\
\hline & & Mungkah lawang \\
\hline & & Miles \\
\hline Zona 2 & Pengawak & Luk Nerudut \\
\hline & & Agem Kiri \\
\hline
\end{tabular}




\begin{tabular}{|l|l|l|}
\hline & & Milpil \\
\hline & & Ngepik \\
\hline Zona 3 & $\begin{array}{l}\text { Pengecet dan } \\
\text { Pakaad }\end{array}$ & Ngenjet \\
\hline & & $\begin{array}{l}\text { Agem Kiri dan } \\
\text { kanan }\end{array}$ \\
\hline & & Nyereseg \\
\hline $\begin{array}{l}\text { Zona } \\
\text { Penutup }\end{array}$ & $\begin{array}{l}\text { Sembah } \\
\text { penutup }\end{array}$ & $\begin{array}{l}\text { Gerakan Sembah } \\
\text { penutup }\end{array}$ \\
\hline
\end{tabular}

Simulasi 3D digunakan untuk melihat gerakan yang telah dibuat ataupun gerakan yang sudah terdapat pada robot. Gambar 4 merupakan tampilan simulasi 3D RoboPlusmotion pada robot penari.

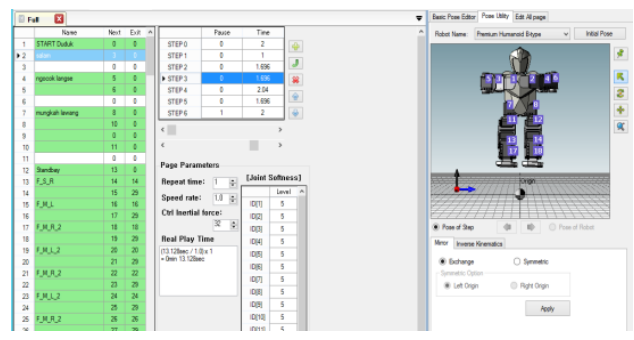

Gbr 4. Tampilan Simulasi 3D RoboPlusMotion

\subsubsection{RoboPlusTask}

RoboPlusTask merupakan software yang bersisikan list perintah, synatx dan pengkodean program yang membuat robot bergerak secara otomatis dan dapat berjalan dengan seimbang. Struktur bahasa pemograman software ini menyerupai struktur bahasa pemograman C. Proses pembuatan program diawali dari "Start Program" samapai dengan "End Program" yang selanjutnya bentuk-bentuk isntruksi code pemograman dapat dipilih pada list box yang ada. Gambar berikut ini merupakan bentuk-bentuk instruksi code yang terdapat pada RoboPlusTask.

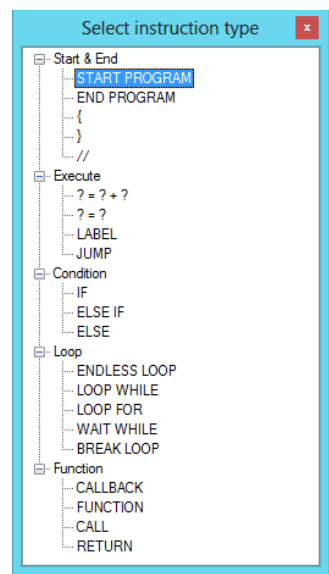

Gbr 5. Instruksi Tipe Code RoboPlus Task
Proses pemanggilan gerakan (motion) dan pengaturan waktu jalan perintah yang terdapat pada RoboPlus Motion ditampilkan pada Gambar 6 Berikut.

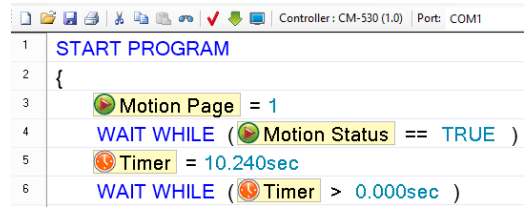

Gbr 6. Coding Pemanggilan Gerakan Dengan Timer

Perintah diatas menginstruksikan untuk memanggil gerakan halaman pertama pada RoboPlus Motion. Proses gerakan tersebut dilakukan robot setelah waktu berjalan selama 10 detik.

\subsubsection{Diagram alir Robot}

Berikut adalah diagram alir program robot penari Legong keraton.

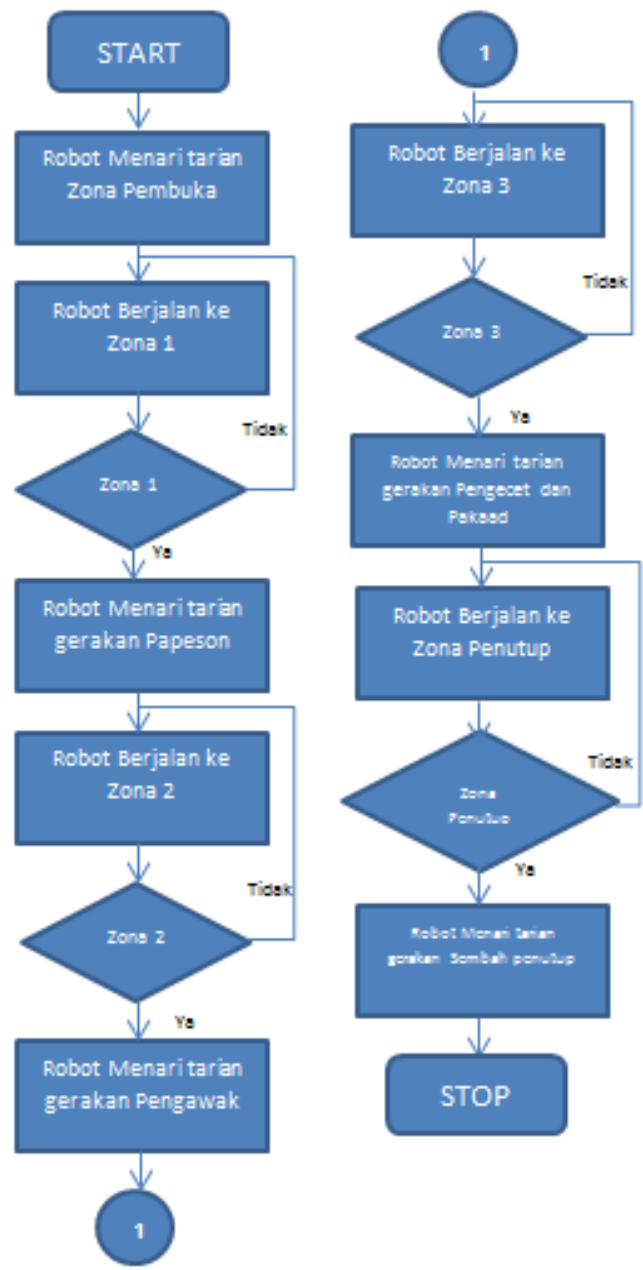

Gbr 7. Diagram Alir Program Robot Penari Legong Keraton 


\section{Hasil Dan Pembahasan}

4.1. Gerakan Tari Robot

Hasil dan pembahasan pada penelitian ini menampilkan gerakan robot untuk setiap zona/struktur tari legong keraton dan durasi lamanya waktu melakukan gerakan-gerakan tersebut Yang ditampilkan pada Tabel 2 .

Tabel 2. Gerakan Robot Penari Legong keratoan

\begin{tabular}{|c|c|c|c|}
\hline $\begin{array}{c}\text { STRUK } \\
\text { TUR } \\
\text { TARI } \\
\text { (zona) }\end{array}$ & $\begin{array}{l}\text { GERA } \\
\text { KAN }\end{array}$ & $\begin{array}{l}\text { CONTOH GAMBAR } \\
\text { GERAKAN ROBOT }\end{array}$ & $\begin{array}{c}\text { DURA } \\
\text { SI } \\
\text { (DETIK } \\
\text { ) }\end{array}$ \\
\hline $\begin{array}{l}\text { Sembah } \\
\text { pembuka }\end{array}$ & $\begin{array}{l}\text { Gerakan } \\
\text { Sembah } \\
\text { Pembuka }\end{array}$ & & 9 detik \\
\hline $\begin{array}{c}\text { STRUK } \\
\text { TUR } \\
\text { TARI }\end{array}$ & $\begin{array}{l}\text { GERA } \\
\text { KAN }\end{array}$ & $\begin{array}{l}\text { CONTOH GAMBAR } \\
\text { GERAKAN ROBOT }\end{array}$ & $\begin{array}{c}\text { DURA } \\
\text { SI } \\
\text { (DETIK } \\
\text { ) }\end{array}$ \\
\hline \multirow[t]{3}{*}{$\begin{array}{l}\text { Papeson } \\
\text { (ZONA 1) }\end{array}$} & $\begin{array}{l}\text { Ngocok } \\
\text { langse }\end{array}$ & & $\begin{array}{l}15 \\
\text { Detik }\end{array}$ \\
\hline & $\begin{array}{l}\text { Mungkah } \\
\text { lawang }\end{array}$ & & $\begin{array}{l}15 \\
\text { Detik }\end{array}$ \\
\hline & Miles & & 4 Detik \\
\hline $\begin{array}{l}\text { Pengawa } \\
\text { k } \\
\text { (ZONA } \\
\text { 2) }\end{array}$ & $\begin{array}{l}\text { Luk } \\
\text { Nerudut }\end{array}$ & & $\begin{array}{l}10 \\
\text { Detik }\end{array}$ \\
\hline
\end{tabular}

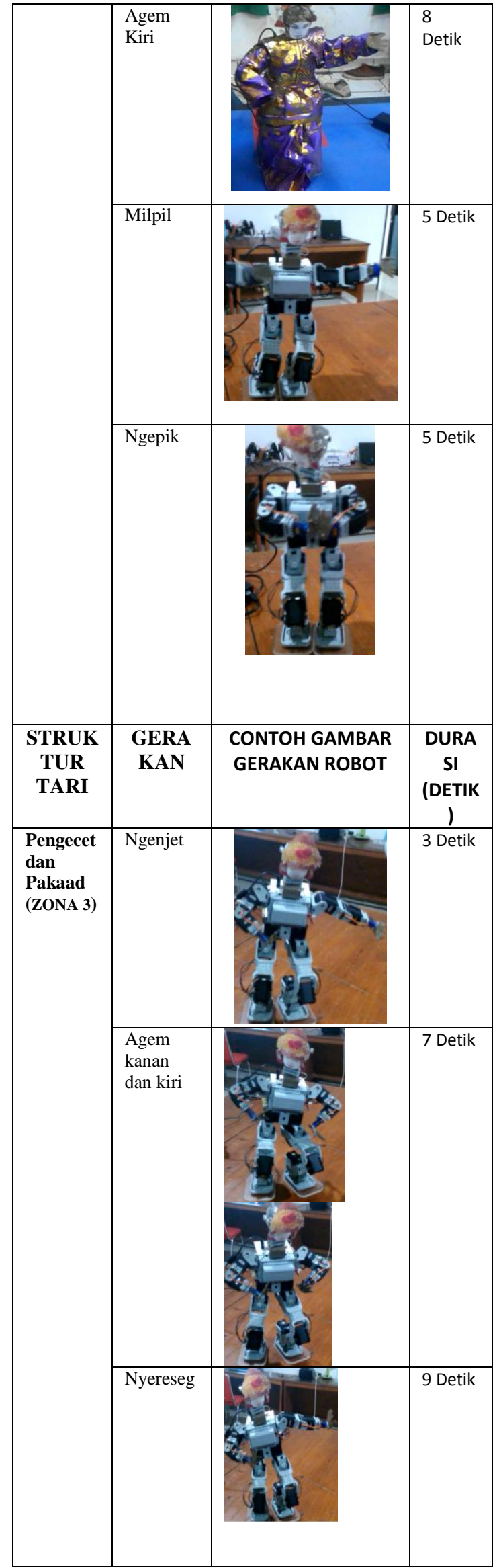




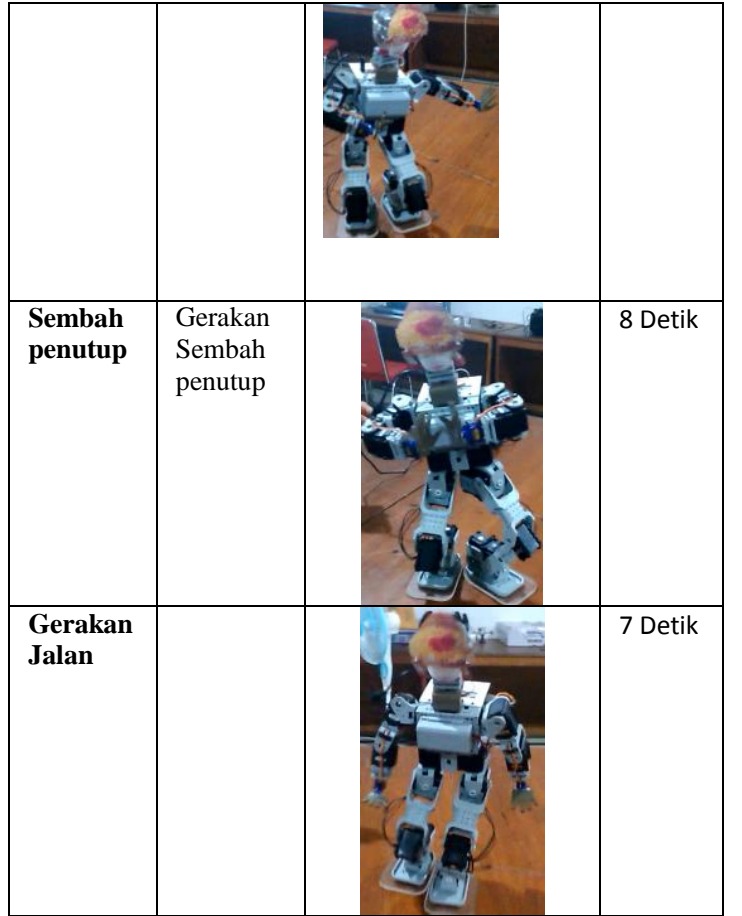

Berdasarkan Tabel 2. Durasi total gerakan robot penari legong keraton adalah 105 detik (1 Menit 45 Detik) yang dihitung dari gerakan sembah pembuka sampai dengan sembah penutup. Untuk berpindah dari satu zona ke zona lainya robot harus berjalan sampai ke zona tujuannya tanpa terjatuh.

\section{Penutup}

\subsection{Kesimpulan}

Terdapat beberapa kesimpulan yang diperoleh dari penelitian ini :

1. Gerakan robot penari terdiri dari beberapa bagian berdasarkan struktur tari legong keraton papeson, pengawak, pengecet dan pakaad yang diawali dengan sembah pembuka dan diakhiri dengan sembah penutup

2. Total waktu durasi seluruh gerakan tari robot adalah 105 detik

3. Software RoboPlus Manger digunakan untuk menempatan ID servo, Softaware RoboPlusMotion digunakan untuk membuat gerakan-gerakan tari dan RoboPlusTask digunakan untuk menggabungkan gerakan-gerakan tari yang telah dibuat

4. Tumpuan kaki robot saat melakukan gerak tari dan jalan sangat mempengaruhi keseimbangan robot.

\subsection{Saran}

Adapun saran dan pengembangan dari penelitian ini yaitu

1. Perlu dipertimbangkan bobot berat robot, dikarenakan kekuatan torsi servodynamixle yang terbatas.

2. Perlu Ketelitian untuk penempatan pemograman nilai servo pada bagian kaki sangat berpengaruh terhadap keseimbangan gerakan robot.

\section{Refrensi}

[1] Tim Juri KRSI, 2014, "Panduan Kontes Robot Seni Indonesi 2014", Jakarta.

[2] ROBOTIS, 2014, "Default Program (Bioloid Premium) [Online]",diakses di: http://www.robotis .com/download/doc/BIO_PRM_Humanoid_ASM.pdf

[3] Arifin W, 2013, "Robot Penari Hanoman Duta Dengan Sensor Suara Built-In Mikrokontroler CM-530", Jurnal Ilmiah Universitas Surabaya Vol.2 No.2, Surabaya.

[4] Sancaya , 2012, "Paper Tari Legong Keraton", diakses di: http://sancayaanca. blogspot.com/2012/07/paper-tarilegong-kraton_7062.html

[5] Tim Penyusun, 2012,"Laporan Restorasi Robot ARM", Laboratorium Teknik kendali JTE Fatek UNSRAT, Manado.

[6] Putro D, 2010, "Rancang Bangun Robot Cerdas Semut Menggunkan Mikrokontroler ATMEGA 16 Untuk Menentukan Lintasan Terpendek", Jurusan Teknik Elektro Fakultas Teknik UNSRAT, Manado. 